\title{
Role of Microtubules in the Rapid Regulation of Renal Phosphate Transport in Response to Acute Alterations in Dietary Phosphate Content
}

\author{
Marius Lötscher, Brigitte Kaissling, Jürg Biber, Heini Murer, and Moshe Levi \\ With the technical assistance of Paul Wilson and Shelly Nguyen \\ Department of Internal Medicine, University of Texas Southwestern Medical Center, and Veterans Affairs Medical Center, Dallas, Texas \\ 75216; and Institutes of Anatomy and Physiology, University of Zürich-Irchel, Switzerland
}

\begin{abstract}
Renal proximal tubular response to acute administration of a low Pi diet is characterized by a rapid adaptive increase in apical brush border membrane (BBM) Na-Pi cotransport activity and $\mathrm{Na}-\mathrm{Pi}$ cotransporter protein abundance, independent of a change in Na-Pi cotransporter mRNA levels (Levi, M., M. Lötscher, V. Sorribas, M. Custer, M. Arar, B. Kaissling, H. Murer, and J. Biber. 1994. Am. J. Physiol. 267: F900-F908). The purposes of the present study were to determine if the acute adaptive response occurs independent of de novo protein synthesis, and if microtubules play a role in the rapid upregulation of the Na-Pi cotransporters at the apical BBM. We found that inhibition of transcription by actinomycin $\mathrm{D}$ and translation by cycloheximide did not prevent the rapid adaptive response. In addition, in spite of a 3.3-fold increase in apical BBM Na-Pi cotransporter protein abundance, there was no change in cortical homogenate Na-Pi cotransporter protein abundance. Pretreatment with colchicine, which resulted in almost complete disruption of the microtubular network, abolished the adaptive increases in BBM Na-Pi cotransport activity and $\mathrm{Na}-\mathrm{Pi}$ cotransporter protein abundance. In contrast, colchicine had no effect on the rapid downregulation of $\mathrm{Na}-\mathrm{Pi}$ cotransport in response to acute administration of a high Pi diet. We conclude that the rapid adaptive increase in renal proximal tubular apical BBM Na-Pi cotransport activity and $\mathrm{Na}-\mathrm{Pi}$ cotransporter abundance is independent of de novo protein synthesis, and is mediated by microtubule-dependent translocation of presynthesized Na-Pi cotransporter protein to the apical BBM. (J. Clin. Invest. 1997. 99:1302-1312.) Key words: Na-Pi cotransport - transcription - translation - microtubules • protein trafficking
\end{abstract}

\section{Introduction}

Changes in dietary phosphate $(\mathrm{Pi})$ content have a major regulatory effect on Pi reabsorption in the kidney. Dietary Pi restriction is associated with an adaptive increase of the overall proximal tubular capacity for Pi uptake through the apical brush border membrane $(\mathrm{BBM})^{1}(1-5)$. The adaptive phenomenon also occurs in renal tubular cells grown in culture upon lowering of the culture media content of $\mathrm{Pi}(6-8)$. The increase

Address correspondence to Moshe Levi, M.D., 4500 South Lancaster Rd., Dallas, TX 75216. Phone: 214-376-5451 x5526; FAX: 214-3727948; E-mail: MMJJL@AOL.COM

Received for publication 22 August 1996 and accepted in revised form 8 January 1997.

The Journal of Clinical Investigation

Volume 99, Number 6, March 1997, 1302-1312 in Pi uptake at the apical membrane in response to the in vivo or cell culture Pi restriction is mediated by an increase of $V_{\max }$ of sodium gradient-dependent phosphate transport (Na-Pi cotransport).

In a recent study in the rat, we found that in response to chronic (8-d) dietary Pi restriction the adaptive increase in BBM Na-Pi cotransport activity was associated with parallel increases in BBM type II ( NaPi-2) Na-Pi cotransport protein and mRNA abundances (9). These results were in agreement with previous studies which indicated that adaptation to chronic Pi restriction can be abolished by inhibitors of transcription and protein synthesis $(6,7,10)$. In contrast, we found out that in response to acute $(2 \mathrm{~h})$ dietary $\mathrm{Pi}$ restriction the rapid adaptive increase in $\mathrm{BBM} \mathrm{Na}-\mathrm{Pi}$ cotransport activity was associated with a parallel increase in BBM Na-Pi cotransport protein abundance, but no change in Na-Pi mRNA abundance (9). The results of that study suggested that the acute upregulation of BBM Na-Pi cotransport activity could be mediated by mechanisms independent of de novo protein synthesis.

The purpose of this study was first to provide further evidence whether the acute adaptive increase in renal proximal tubular Na-Pi cotransport activity occurs independent of de novo protein synthesis. Furthermore, in view of recent evidence suggesting an important role for microtubules in the regulation of the trafficking and the activity of a number of channels and transport proteins (11-17), the second purpose of our study was to determine if microtubules play a role in the rapid upregulation of $\mathrm{Na}-\mathrm{Pi}$ cotransport activity in response to acute administration of a low Pi diet.

\section{Methods}

Experimental animals. The experiments were performed with 6-8wk-old male Sprague-Dawley rats. After arrival at the Animal Care Facility, the animals were first stabilized on a control diet for $5 \mathrm{~d}$, and they were then placed on high phosphate $(1.2 \% \mathrm{Pi})$ or low phosphate $(0.1 \% \mathrm{Pi})$ diets, which were otherwise identical in their mineral, electrolyte, protein, carbohydrate, fat, and calorie content (Teklad, Madison, WI). The rats were trained to consume their diet between 10:00 a.m. and 12:00 noon each day. By the second day all rats consumed the amount of diet (16-20 g) which they usually eat during a 24-h period when fed ad libitum. The rats were pair-fed the high or low Pi diets for seven consecutive days.

On the eighth day, the following four groups of rats were studied: group 1, rats that were chronically fed $1.2 \%$ Pi diet and continued on $1.2 \%$ Pi diet (chronic high Pi diet); group 2, rats that were chronically fed $1.2 \%$ Pi diet and on the day of the experiment were acutely fed $0.1 \%$ Pi diet for $2 \mathrm{~h}$ (acute low Pi diet); group 3, rats that were chronically fed $0.1 \%$ Pi diet and continued on $0.1 \%$ Pi diet (chronic low Pi

1. Abbreviations used in this paper: $\mathrm{BBM}$, brush border membrane; PCT, proximal convoluted tubule. 
diet); and group 4, rats that were chronically fed $0.1 \%$ Pi diet and on the day of the experiment were acutely fed $1.2 \%$ Pi diet for $2 \mathrm{~h}$ (acute high Pi diet).

In experiments designed to study the role of transcription and/or translation in the rapid upregulation of renal phosphate transport in response to an acute administration of a low Pi diet, the rats were trained and chronically adapted on a high Pi diet as above. On the seventh day, $24 \mathrm{~h}$ before study the rats were treated with actinomycin $\mathrm{D}(0.12 \mathrm{mg} / \mathrm{kg}$ body wt, given intraperitoneally), cycloheximide $(0.5$ $\mathrm{mg} / \mathrm{kg}$ body wt, given intraperitoneally), or vehicle (saline). On the eighth day, the rats were then fed either the high Pi (chronic high $\mathrm{Pi}$ ) or low $\mathrm{Pi}$ (acute low $\mathrm{Pi}$ ) diets for $2 \mathrm{~h}$ and then the rats were killed. The doses of actinomycin D and cycloheximide used in this study were identical to doses which have been shown previously to inhibit transcription and translation, respectively, and to prevent chronic (3-d) adaptation of BBM Na-Pi cotransport activity in response to a low Pi diet $(10,18)$.

In experiments designed to study the role of microtubules in the regulation of the renal Pi transporter in response to acute alterations in dietary Pi content, the rats were trained and chronically adapted to high and low Pi diets as above. On the eighth day, on the day of the study, $6 \mathrm{~h}$ before time of killing, the rats were treated with colchicine, $1.0 \mathrm{mg} / \mathrm{kg}$ body wt, dissolved in saline, and administered via intraperitoneal injection (19), or vehicle (saline), and then $2 \mathrm{~h}$ before time of killing they were fed the high or low Pi diets as outlined above. In preliminary experiments, we demonstrated that this dose of colchicine causes complete disruption of the microtubular network as determined by immunohistochemistry (see Results).

Eight individual rats were studied in each of the experimental groups for BBM isolation and six individual rats were studied in each of the experimental groups for immunohistochemistry.

Preparation of BBM vesicles. On the day of the experiment at the end of the 2-h feeding period, the rats were anesthetized with intraperitoneal administration of pentobarbital, blood was drawn from the aorta, and the kidneys were rapidly removed. Thin slices were cut at $4^{\circ} \mathrm{C}$ from the superficial cortex and homogenized with a Polytron in a buffer consisting of (mM): 300 DL-mannitol, 5 EGTA, 0.5 phenylmethylsulfonyl fluoride, and 16 Hepes ( $\mathrm{pH} 7.5$ with Tris). BBM were precipitated from this homogenate by $\mathrm{Mg}^{2+}$ precipitation and differential centrifugation as described $(5,20)$. The final pellet was resuspended in a buffer of $300 \mathrm{mM}$ mannitol, and $16 \mathrm{mM}$ Hepes-Tris, $\mathrm{pH}$ 7.5. Purity of BBM preparations was enzymatically assayed as published $(5,20)$.

Sodium gradient-dependent phosphate transport ( $\mathrm{Na-Pi}$ cotransport) measurements. Transport measurements were performed in freshly isolated BBM vesicles, by uptake of $0.1 \mathrm{mM} \mathrm{PO}_{4}$ (a mix of $\mathrm{K}_{2} \mathrm{HPO}_{4}$ plus $\mathrm{KH}_{2} \mathrm{PO}_{4}$, pH 7.4), plus $\mathrm{K}_{2} \mathrm{H}^{32} \mathrm{PO}_{4}$ (DuPont-NEN Research Products, Boston, MA) as a radio tracer (4 Ci/ml uptake medium, 3,000 Ci/mmol), and an inwardly directed sodium gradient (120 $\mathrm{mM} \mathrm{NaCl}$ ) followed by rapid filtration. Uptake was measured at $10 \mathrm{~s}$ which represents initial linear phase of transport.

SDS-PAGE and immunoblotting. Aliquots of cortical homogenate and $\mathrm{BBM}$ were denatured for $2 \mathrm{~min}$ at $95^{\circ} \mathrm{C}$ in $2 \% \mathrm{SDS}, 10 \%$ glycerol, $0.5 \mathrm{mM}$ EDTA, and $95 \mathrm{mM}$ Tris- $\mathrm{HCl}$, pH 6.8 (final concentrations), and $20 \mu \mathrm{g}$ cortical homogenate or $5 \mu \mathrm{g}$ BBM protein per lane was separated on $10 \%$ polyacrylamide gels according to the method of Laemmli (21) and electrotransferred on nitrocellulose paper (22). After blockage with 5\% fat-free milk powder with $1 \%$ Triton $\mathrm{X}-100$ in Tris-buffered saline $(20 \mathrm{mM}, \mathrm{pH} 7.3)$, Western blots were performed with antiserum against NaPi-2 (23) at dilution of 1:4,000. Primary antibody binding was visualized with chemiluminescence technique (Pierce, Rockford, IL) and quantified by PhosphorImager (Bio-Rad Laboratories, Richmond, CA). For peptide protection, antigenic peptides were included at a concentration of $100 \mu \mathrm{g} / \mathrm{ml}$. Prestained molecular weight marker proteins (Bio-Rad Laboratories) were run in parallel.

Immunohistochemistry. Rats were anesthetized with thiopental (Pentothal, $100 \mathrm{mg} / \mathrm{kg}$ body $\mathrm{wt}$ ), injected intraperitoneally, and per- fused retrogradely at a pressure of $1.38 \mathrm{hp}$ through the abdominal aorta with a fixative of $3 \%$ paraformaldehyde and $0.05 \%$ picric acid in a 6:4 mixture of $0.1 \mathrm{M}$ cacodylate buffer ( $\mathrm{pH} 7.4$, adjusted to 300 mosmol with sucrose) and $10 \%$ hydroxyethyl starch (Pentaspan; DuPont, Wilmington, DE). After 5 min of fixation, the fixative was replaced by perfusion for $5 \mathrm{~min}$ with cacodylate buffer.

Slices of fixed kidneys were frozen in liquid propane cooled by liquid nitrogen onto 0.5 -mm-thin corks slices (glue: embedding medium). Sections $3-\mu \mathrm{m}$-thick were cut at $-22^{\circ} \mathrm{C}$ in the cryomicrotome, mounted on chromalum/gelatin-coated glass slides, thawed, and stored in cold PBS until use.

For $\mathrm{NaPi}-2 / \alpha$-tubulin and $\mathrm{NaPi}-2 /$ actin immunofluorescence staining, sections were pretreated for 10 min with $3 \%$ milk powder in PBS containing $0.3 \%$ Triton $\mathrm{X}-100$. They were then covered overnight at $4^{\circ} \mathrm{C}$ with a rabbit anti-rat polyclonal antibody against $\mathrm{NaPi}-2$ protein (23) at 1:500 dilution, or a mouse monoclonal antibody against $\alpha$-tubulin (Sigma Chemical Co., St. Louis, MO) at 1:1,000 dilution in PBS/ milk powder. The sections were rinsed three times before incubation for $1 \mathrm{~h}$ at $4^{\circ} \mathrm{C}$ with the secondary antibodies swine anti-rabbit IgG conjugated to FITC (Dakopatts, Glostrup, Denmark) and goat antimouse IgG conjugated to $\mathrm{Cy} 3^{\mathrm{TM}}$ (Jackson ImmunoResearch, West Grove, PA) diluted 1:50 and 1:200, respectively, in PBS/milk powder. Acin filaments were visualized with phalloidin conjugated to rhodamine (Molecular Probes, Eugene, OR) incubated at a dilution of 1:100 together with the secondary FITC-conjugated antibodies.

For NaPi-2/Golgi and NaPi-2/lysosome immunofluorescence staining, the sections were covered overnight at $4^{\circ} \mathrm{C}$ with antibody against NaPi-2 protein at 1:500 dilution (23), a mouse monoclonal antibody against the Golgi membrane protein 58K (Sigma Chemical Co.) at 1:500 dilution (24-26), or a mouse anti-rat antibody against the lysosomal membrane glycoprotein lgp120 at 1:200 dilution (27-30), in $\mathrm{PBS} /$ milk powder.

After being rinsed with water, the sections were coverslipped using DAKO-Glycergel (Dakopatts) plus 2.5\% 1,4-diazabicyclo\{2.2.2\}octane (DABCO; Sigma Chemical Co.) as a fading retardant. They were studied with a laser scanning microscope (Zeiss, Oberkochen, Germany) by confocal fluorescence imaging.

Statistical analysis. All the data were expressed as mean \pm SE. A two-tailed unpaired Student's $t$ test and/or a one-way ANOVA with Student-Newman-Keul's multiple range test was used to compare results between control and experimental groups. Significance was accepted at $P<0.05$.

\section{Results}

Absence of a role for transcription and translation in the rapid upregulation of Na-Pi cotransport. The purpose of the first series of experiments was to determine whether the rapid upregulation of BBM Na-Pi cotransport activity in response to acute $(2 \mathrm{~h})$ administration of a low Pi diet is dependent on transcriptional and/or translational mechanisms. In agreement with our earlier study, we found that after the administration of low Pi diet for $2 \mathrm{~h}$ there was a rapid upregulation of BBM Na-Pi cotransport activity (Fig. 1, left) and BBM Na-Pi cotransport protein abundance (Fig. 2, right). Inhibition of transcription with actinomycin D (Fig. 1, right) or inhibition of translation with cycloheximide (Fig. 1, middle) did not prevent the rapid upregulation of BBM Na-Pi cotransport activity in response to a low Pi diet.

In the next series of studies, we performed Western blots with cortical homogenate samples and BBM isolated from rats chronically fed a high Pi diet and acutely a low Pi diet. After the administration of a low Pi diet there was no increase in Na-Pi cotransporter abundance in the cortical homogenate (Fig. 2 , left) which presumably represents the total amount of Na-Pi 


\section{Control}

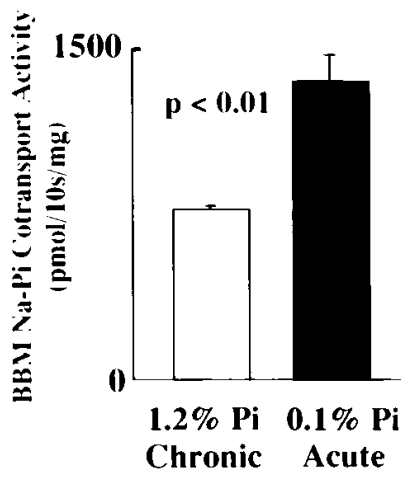

Cycloheximide

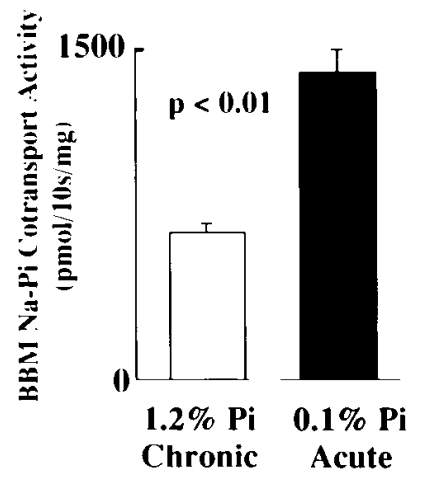

Actinomycin D

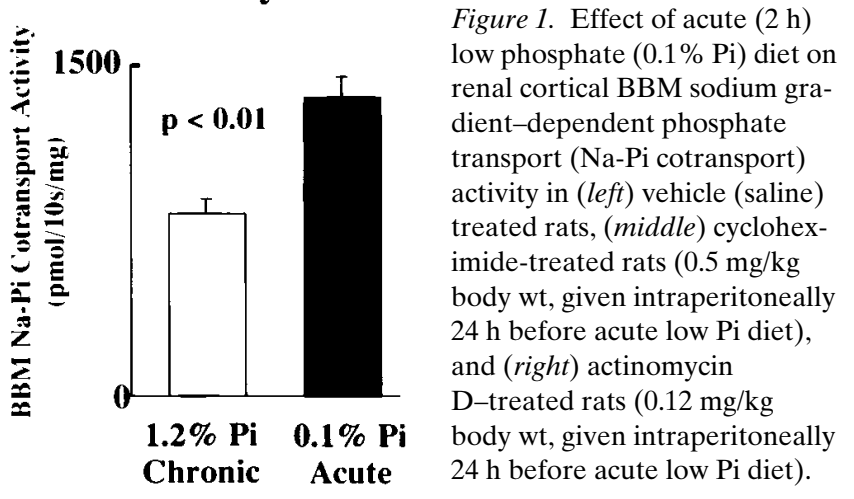

cotransporters, whereas there was a marked 3.3-fold increase in BBM Na-Pi cotransport protein abundance (Fig. 2, left).

Therefore, the results of these studies indicate that acute upregulation of $\mathrm{Na}-\mathrm{Pi}$ cotransport activity is independent of transcription and translation and is probably mediated by translocation of the presynthesized $\mathrm{Na}$-Pi cotransport protein to the apical BBM.

Role for microtubules in the rapid upregulation of $\mathrm{Na}-\mathrm{Pi}$ cotransport. The purpose of these experiments was to determine if microtubules play a role in the presumable rapid translocation of the Na-Pi cotransport protein in response to a low Pi diet. Pretreatment of rats chronically fed a high Pi diet with colchicine resulted in almost complete disruption of the microtubules. This was demonstrated by immunohistochemistry using an antibody specific for $\alpha$-tubulin. In control rats staining for $\alpha$-tubulin revealed a dense network of microtubules spanning all of the proximal convoluted tubule (PCT) cell except the brush border (Fig. 3, $C$ and $D$ ). After $6 \mathrm{~h}$ of colchicine treatment, microtubules had vastly disappeared, except for some microtubular remnants in the apical cell portion (Fig. 3, $G$ and $H)$. Microfilaments, on the other hand, seemed to be unaffected by the colchicine treatment, as revealed by a F-actin specific staining with phalloidin-rhodamine (Fig. 4).

In association with its deleterious effect on microtubular integrity, colchicine treatment prevented the upregulation of
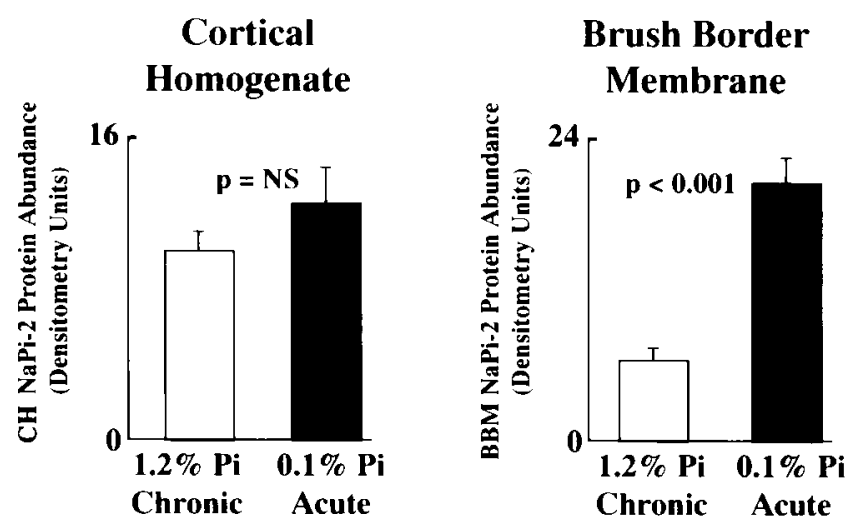

Figure 2. Effect of acute $(2 \mathrm{~h})$ low phosphate $(0.1 \% \mathrm{Pi})$ diet on renal cortical homogenate $(\mathrm{CH})$ and BBM type II renal Na-Pi cotransporter $(\mathrm{NaPi}-2)$ protein abundance as determined by Western blotting and densitometry (see Methods for details).
BBM Na-Pi cotransport activity (Fig. 5) and the BBM expression of NaPi-2 protein as determined by Western blotting (Fig. 5 ) in response to acute administration of a low Pi diet.

The prevention of NaPi-2 protein upregulation in the BBM was also evidenced by immunohistochemistry. After chronic adaptation of control rats to a high Pi diet, PCT in the superficial and midcortex showed only faint staining for $\mathrm{NaPi}-2$ protein in the brush border, whereas some intracellular compartments in the vicinity of the nuclei were clearly positive (Fig. 3 $A$ ). Acute adaptation from a high to a low Pi diet led to strong $\mathrm{NaPi}-2$ protein specific staining in the brush border and in parallel, to a decreased intracellular staining (Fig. $3 \mathrm{~B}$ ). The nature of the intracellular compartments containing NaPi-2 protein is addressed in a subsequent section. When rats chronically adapted to high Pi were treated with colchicine, the intracellular staining for NaPi-2 protein had lost much of its perinuclear localization and was spread throughout the cell in small vesicles (Fig. 3 E). Altering the diet of colchicine-treated rats acutely from high to low Pi appeared to be without effect on NaPi-2 protein expression (Fig. $3 F$ ).

Absence of a role for microtubules in the rapid downregulation of $\mathrm{Na}$-Pi cotransport. The purpose of these experiments was to determine whether microtubules also played a role in the rapid downregulation of $\mathrm{Na}-\mathrm{Pi}$ cotransport activity in response to a high Pi diet. In rats chronically fed a low Pi diet, the acute (2-h) administration of a high Pi diet results in rapid downregulation of BBM Na-Pi cotransport activity (Fig. 6) and BBM Na-Pi cotransport protein abundance (Figs. 6 and 7, $A$ and $B)$. Pretreatment of rats chronically fed a low Pi diet with colchicine resulted in almost complete disruption of the microtubules in PCT, as revealed by immunohistochemistry (Fig. 7, $G$ and $H$ ) and described above for rats adapted chronically to a high Pi diet. In spite of its deleterious effect on the microtubular cytoskeleton, colchicine treatment of rats chronically adapted to a low Pi diet neither lead to an essential decrease of BBM Na-Pi cotransport activity or BBM NaPi-2 protein abundance (Figs. 6 and $7 E$ ), nor prevent the downregulation of Na-Pi cotransport activity or the expression of $\mathrm{Na}-\mathrm{Pi}$ cotransport protein at the level of the proximal tubular BBM (Figs. 6 and $7 F$ ).

Nature of the intracellular compartments containing $\mathrm{NaPi}-2$ protein. To determine the role of the intracellular NaPi-2 protein in the rapid adaptation to dietary $\mathrm{Pi}$, we performed further immunohistochemical staining for $\mathrm{NaPi}-2$, Golgi membrane, and lysosomal membrane. The staining of intracellular NaPi-2 

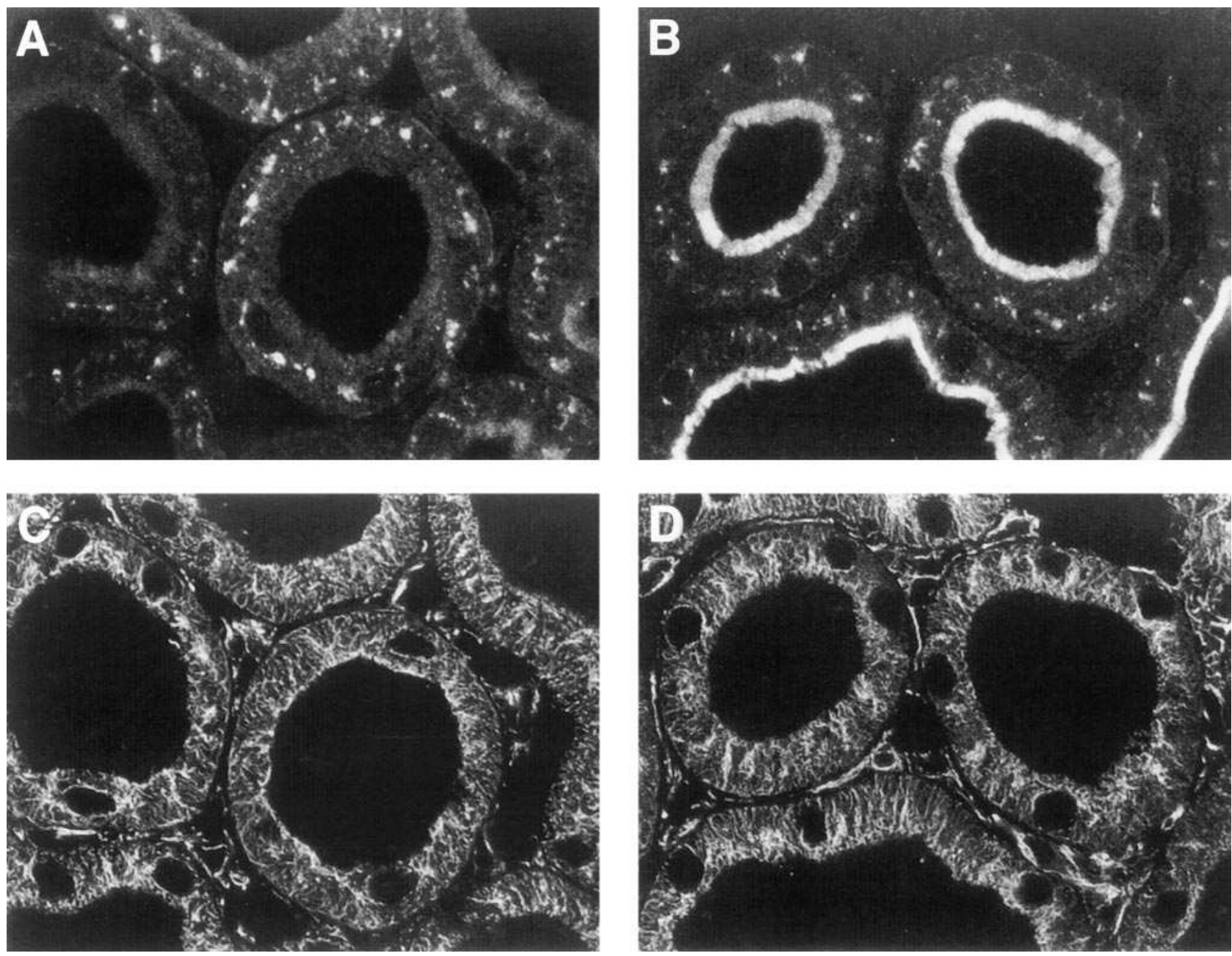

Figure 3. Immunohistochemistry, demonstrating the effect of colchicine on rapid upregulation of apical NaPi-2 protein and on microtubule integrity. Cryostat sections from rat kidneys adapted chronically to a high Pi diet $(A, C, E$, and $G$ ) or acutely from a high to a low Pi diet ( $B, D, F$, and $H)$ were stained by indirect immunofluorescence for NaPi-2 protein $(A, B, E$, and $F)$ and, on consecutive sections, for $\alpha$-tubulin $(C, D, G$, and $H)$. In control rats $(A-D)$, acute adaptation of the kidney to low Pi is associated with a rapid upregulation of NaPi-2 protein at the BBM. Microtubules span the entire cell with a dense network. In colchicine-treated rats $(E-H)$, rapid upregulation of NaPi-2 protein at the BBM is abolished. From the microtubular network, only apical remnants are left. Bar $=10 \mu \mathrm{m}$.

protein, which turned out to be more sensitive several weeks after tissue fixation, was correlated with the localization of the Golgi membrane protein 58K (24-26) and the lysosomal membrane glycoprotein $\operatorname{lgp} 120(27-30)$, respectively.

After chronic adaptation to a high Pi diet, NaPi-2 was detected in the subapical portion and in a perinuclear region, where in part it spatially coincided with the Golgi-like compartment (Fig. 8). In contrast, there was hardly any colocalization of NaPi-2 with the lysosomal compartment (Fig. 9).

Acute adaptation from high Pi diet to low Pi diet led to a depletion of intracellular $\mathrm{NaPi}-2$, leaving a clear staining only in the Golgi-like compartment (Fig. 8).

After chronic adaptation to a low Pi diet, intracellular $\mathrm{NaPi}-2$ was predominantly localized in the region of the Golgilike compartment (Fig. 10), but also at additional sites in the subapical and central cell portions. Again, the overlap between intracellular NaPi-2 and lgp120 staining was minimal (Fig. 11).

Acute adaptation from a low Pi to a high Pi diet led to increased abundance of intracellular $\mathrm{NaPi}-2$, which was detected in the subapical, central, and basal cell portions. Interestingly, a considerable spatial overlap between intracellular NaPi-2 and the lysosomal marker lgp120 staining was observed (Fig. 11).

\section{Discussion}

In this study we demonstrate that in rats chronically fed a high phosphate diet, after the acute administration of a low phosphate diet, the rapid adaptive increase in proximal tubular apical Na-Pi cotransport activity and BBM Na-Pi cotransporter protein abundance occurs independent of de novo synthesis of additional protein units. The rapid adaptation is probably mediated by translocation of presynthesized $\mathrm{Na}$-Pi cotransporter protein to the apical BBM by microtubule-dependent mechanisms.

Two lines of evidence indicate that the rapid adaptive increase in BBM Na-Pi cotransport activity and BBM Na-Pi cotransporter protein abundance occurs independent of de novo protein synthesis. Inhibition of transcription by actinomycin D and translation by cycloheximide do not prevent the rapid upregulation of $\mathrm{Na}-\mathrm{Pi}$ cotransport activity. In addition, in 

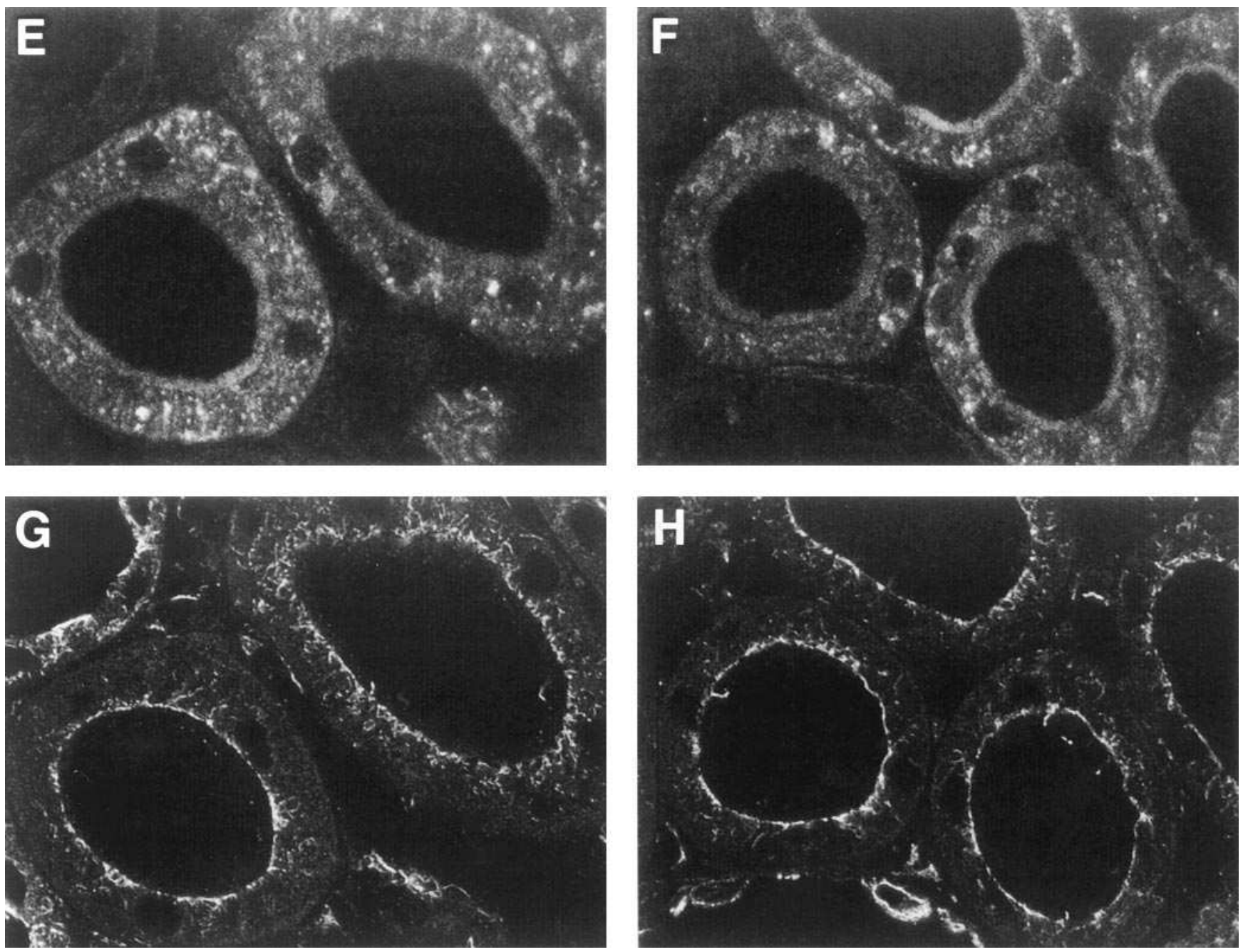

Figure 3 (Continued)
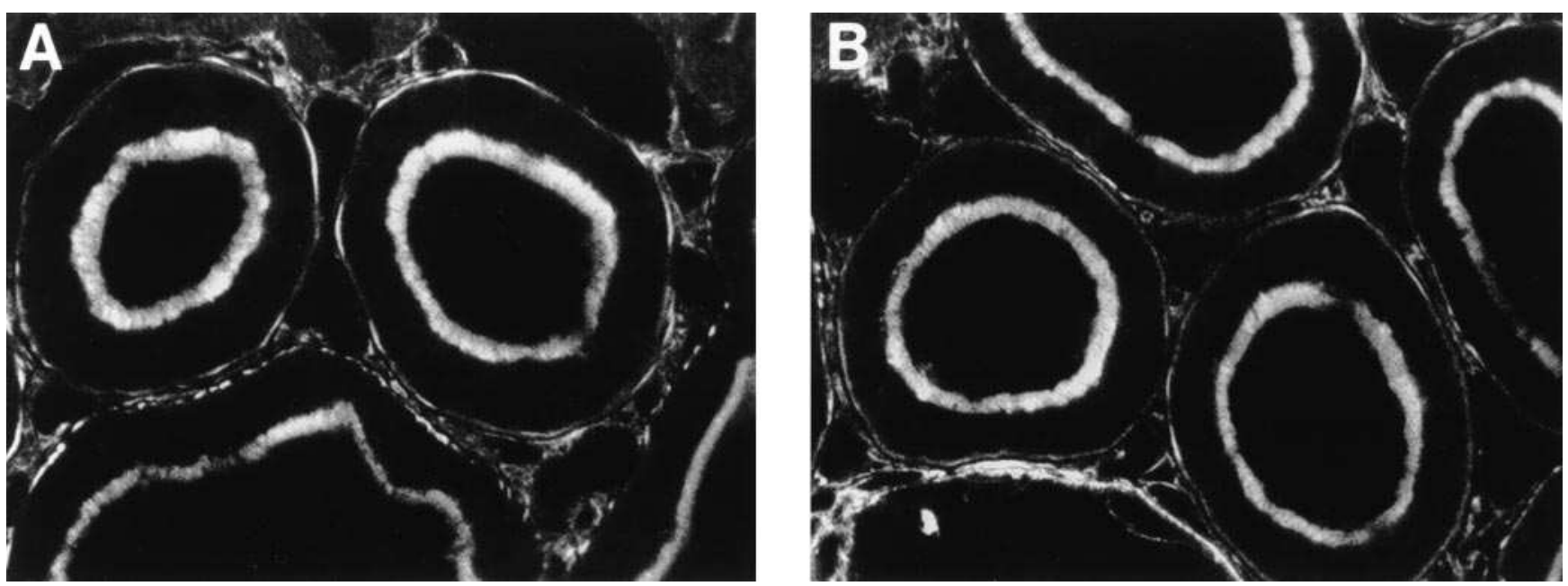

Figure 4. Histochemical detection of F-actin with rhodamine-conjugated phalloidin, revealing no effect of colchicine on the microfilamentous cytoskeleton. The sections shown in $A$ (control) and $B$ (colchicine) correspond to the sections shown in Fig. $3, E$ and $F$, respectively. Bar $=10 \mu m$. 
BBM NaPi-2 Cotransport Activity (pmol/10s/mg)
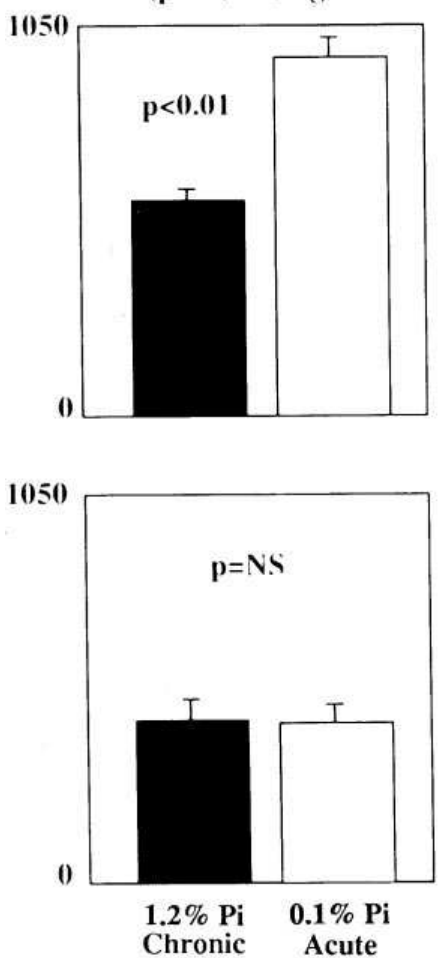

BBM NaPi-2 Protein
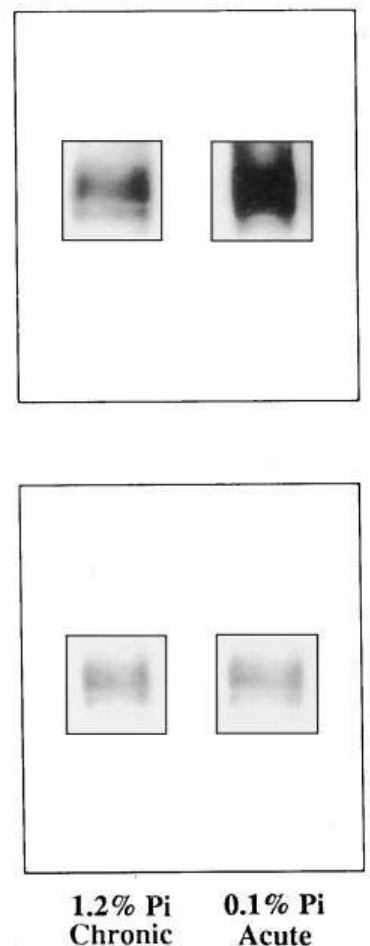

BBM NaPi-2 Protein Abundance (densitometry units)

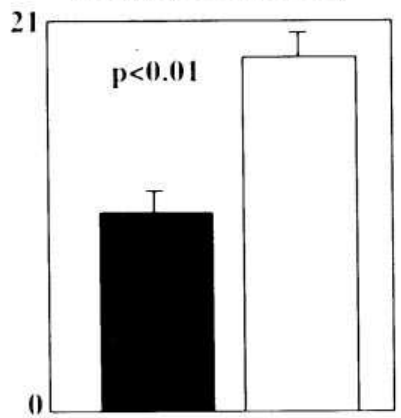

\section{Colchicine}

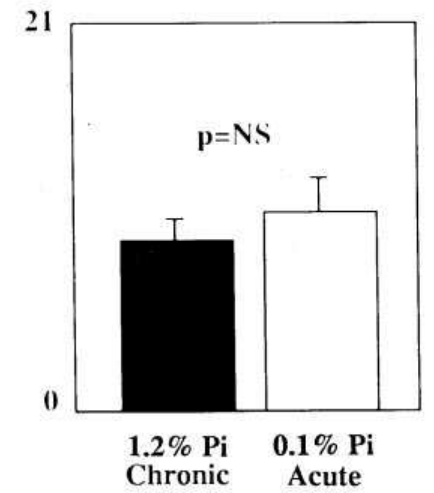

๑) Colchicine

Figure 5. Effect of acute $(2 \mathrm{~h})$ low phosphate $(0.1 \% \mathrm{Pi})$ diet on renal cortical BBM sodium gradient-dependent phosphate transport $(\mathrm{Na}$-Pi cotransport) activity and type II renal Na-Pi cotransporter (NaPi-2) protein abundance in (top) vehicle (saline) treated rats and (bottom) colchicine-treated rats $(1 \mathrm{mg} / \mathrm{kg}$ body wt, given intraperitoneally $4 \mathrm{~h}$ before acute low Pi diet).
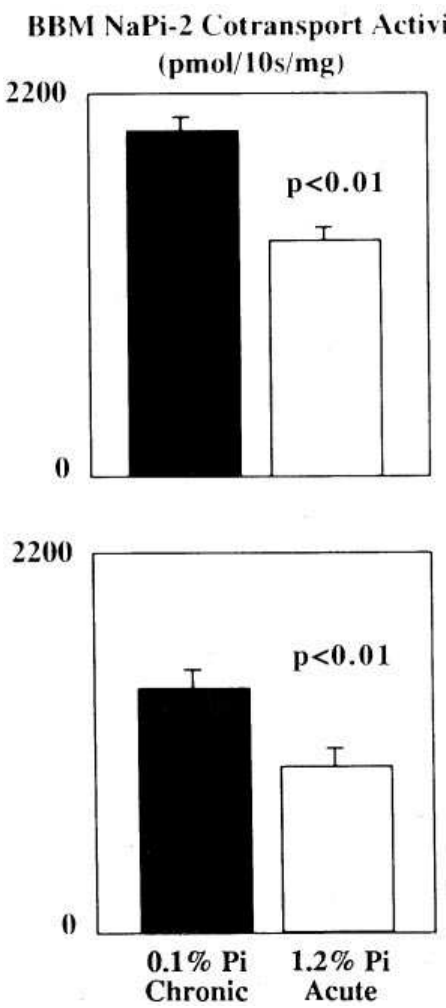

BBM NaPi-2 Protein
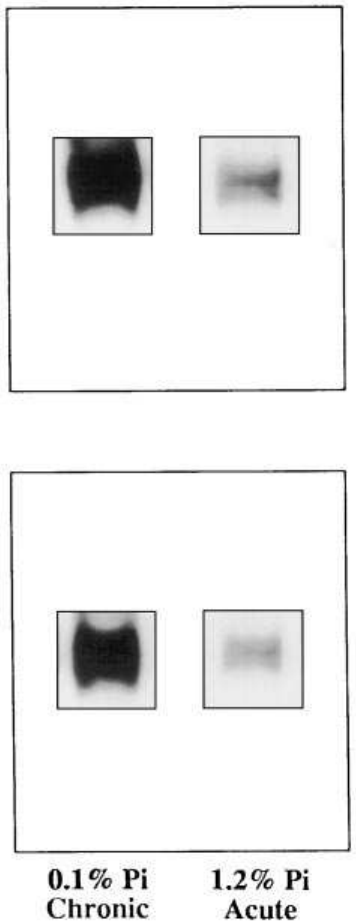

BBM NaPi-2 Protein Abundance (densitometry units)

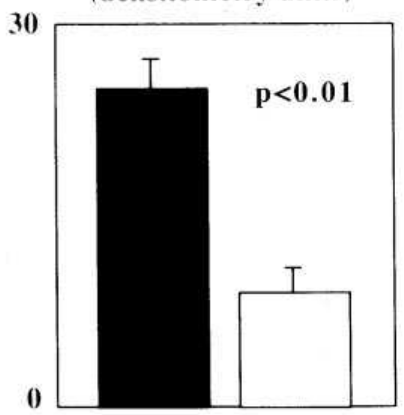

Colchicine

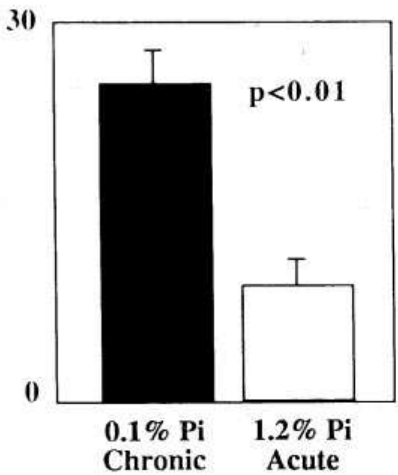

$\oplus$ Colchicine

Figure 6. Effect of acute $(2 \mathrm{~h})$ high phosphate (1-2\% Pi) diet on renal cortical BBM sodium gradient-dependent phosphate transport (Na-Pi cotransport) activity and type II renal Na-Pi cotransporter ( NaPi-2) protein abundance in (top) vehicle (saline) treated rats and (bottom) colchicine-treated rats $(1 \mathrm{mg} / \mathrm{kg}$ body wt, given intraperitoneally $4 \mathrm{~h}$ before acute low Pi diet). 

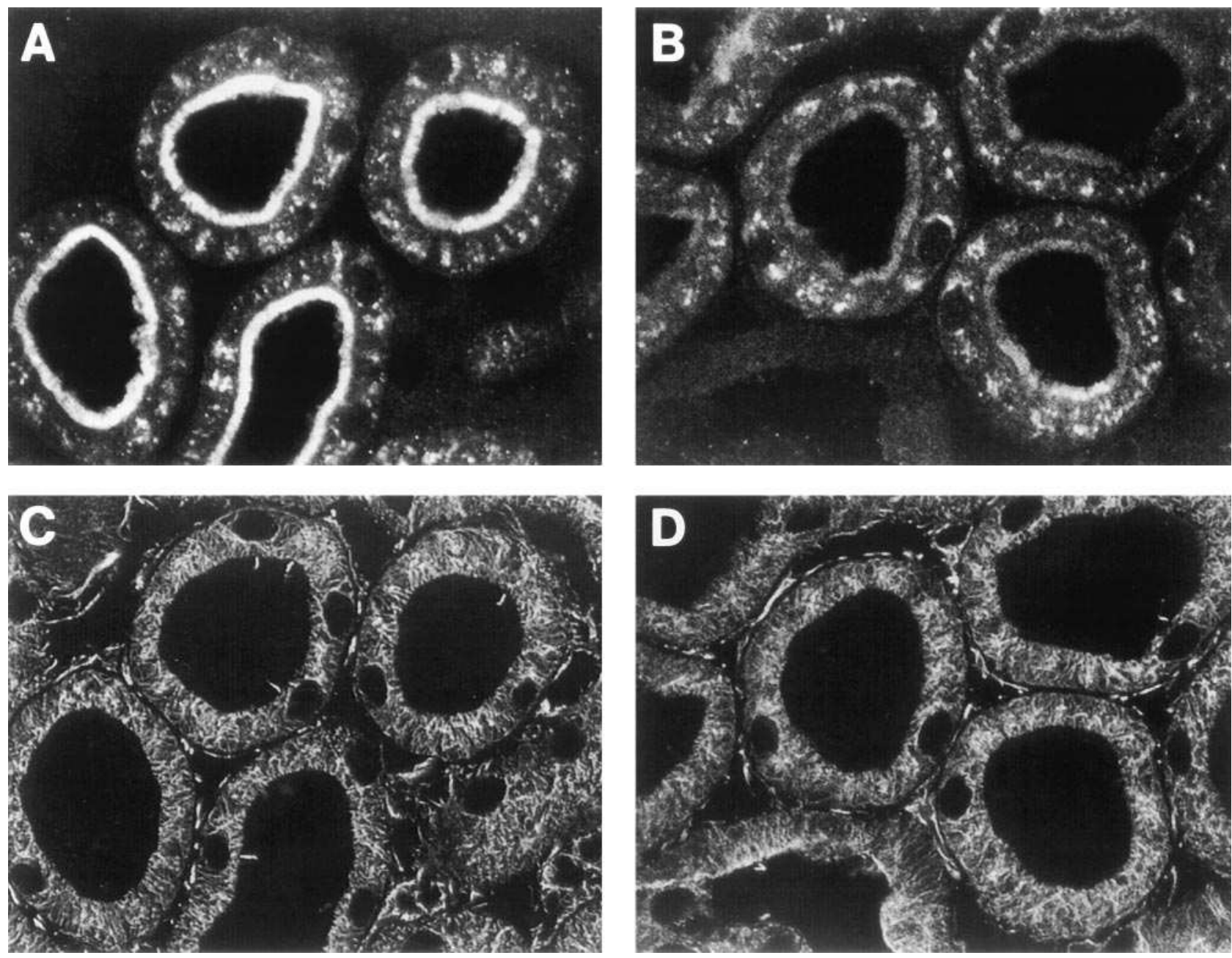

Figure 7. Immunohistochemistry, revealing no effect of colchicine on rapid downregulation of apical NaPi-2 protein. In correspondence to Fig. 3 , these micrographs represent kidneys from rats adapted chronically to low Pi diet $(A, C, E$, and $G)$ or acutely from a low to a high Pi diet $(B, D$, $F$, and $H)$. In control rats $(A-D)$, acute adaptation of the kidney to high $\mathrm{Pi}$ is associated with rapid downregulation of $\mathrm{NaPi}-2$ protein at the BBM. In colchicine treated rats $(E-H)$, the microtubular network is vastly disrupted, but rapid downregulation of NaPi-2 protein at the BBM is still accomplished. Bar $=10 \mu \mathrm{m}$.

response to the acute administration of a low Pi diet the increase in BBM Na-Pi cotransporter protein abundance occurs independent of a change in cortical homogenate Na-Pi cotransporter protein abundance. These results are in agreement with previous in vivo and cell culture studies which showed that the acute adaptive response to a low Pi diet occurs in the absence of changes in Na-Pi mRNA abundance $(9,31)$. In contrast, the chronic adaptive response to a low $\mathrm{Pi}$ diet is characterized by an increase in Na-Pi mRNA abundance $(9,31)$, and furthermore inhibition of transcription and/or translation abolishes the chronic adaptive increase in Na-Pi cotransport activity (6, $7,10)$.

The rapid increase in $\mathrm{NaPi}-2$ protein abundance at the level of the apical BBM, which occurs independent of de novo protein synthesis, has to be dependent on the recruitment of preexisting NaPi-2 protein from an intracellular compartment(s). Evidence for such a recruitment is provided by our immunohistochemical findings that the rapid increase in NaPi-2 protein abundance in the BBM is accompanied with a depletion of intracellular $\mathrm{NaPi}-2$. The nature of the acutely depleted com- partments remains to be determined. It is also unclear why the detected decrease in intracellular $\mathrm{NaPi}-2$ is inferior to the observed increase at the BBM. We assume that $\mathrm{NaPi}-2$ specific immunostaining is more sensitive at the BBM than at intracellular membranes, probably due to a different environment, including chemical modification and changes in $\mathrm{pH}$.

A fraction of the intracellular $\mathrm{NaPi}-2$ in a perinuclear compartment seems to be spared from the acute intracellular $\mathrm{NaPi}-2$ depletion which occurs in response to a low Pi diet. Whether this perinuclear transporter protein is destined for insertion into the BBM or for degradation is not known. However, it seems to strongly colocalize with the Golgi membrane protein $58 \mathrm{~K}$, but not with the lysosomal membrane glycoprotein lgp120. A considerable colocalization of intracellular NaPi-2 with $\operatorname{lgp} 120$ is only found when, in response to acute administration of a high $\mathrm{Pi}$ diet, NaPi-2 protein is rapidly downregulated at the BBM, most likely via internalization and subsequent degradation.

The rapid recruitment of $\mathrm{Na}-\mathrm{Pi}$ cotransported protein from an intracellular compartment(s) to the BBM involves most 

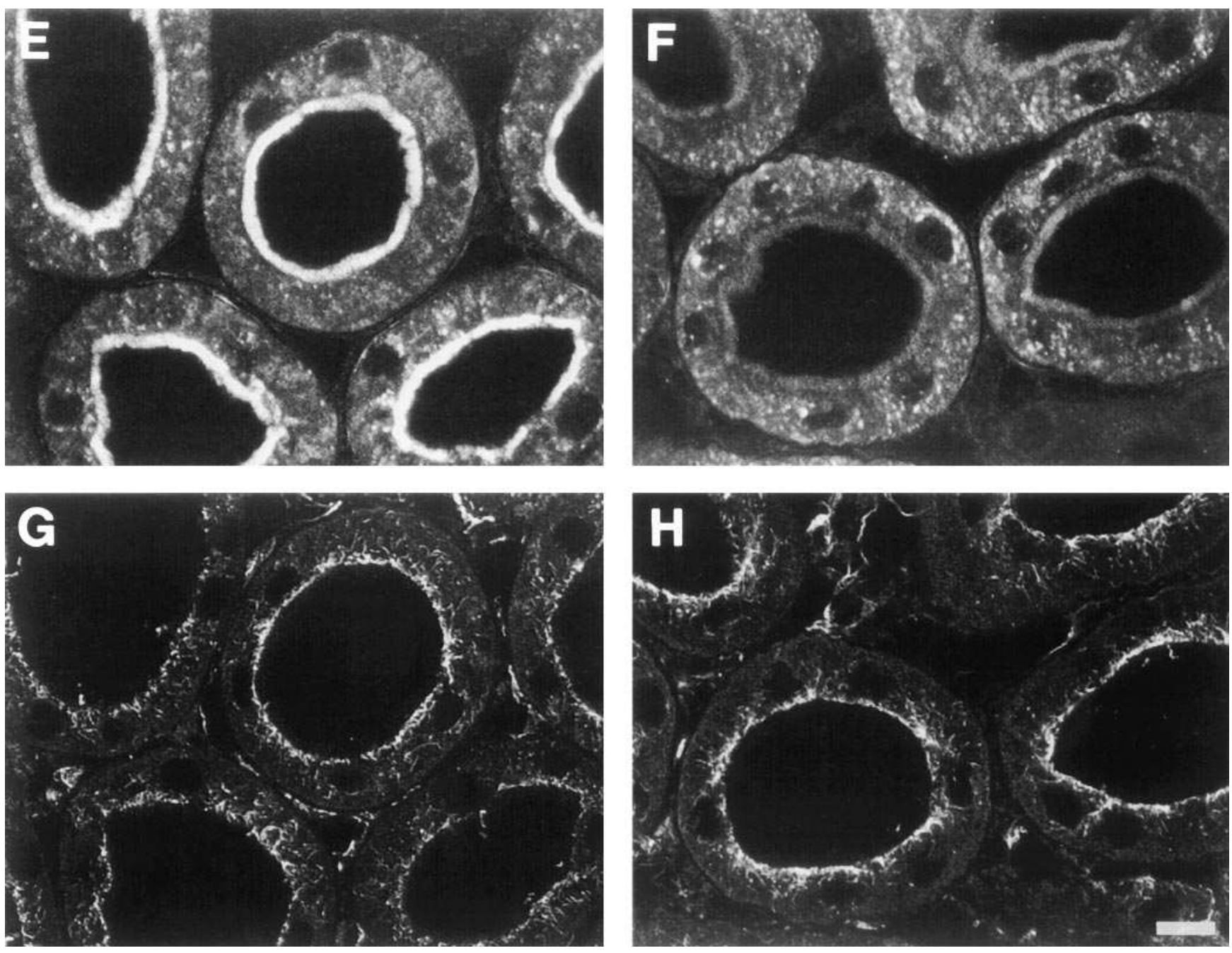

Figure 7 (Continued)

likely a microtubule-dependent translocation. Prior disruption of the microtubular network by colchicine completely prevents the adaptive upregulation of $\mathrm{Na}-\mathrm{Pi}$ cotransport activity and Na-Pi cotransporter protein expression at the level of the proximal tubular apical BBM. Recent studies have demonstrated a similar role for microtubules in the apical targeting of several channel and transport proteins (11-17), including gp330, an endogenous apical membrane glycoprotein (32), the water channels Aquaporin-1 and Aquaporin-2 (33-35), a colonic chloride channel (36), the vacuolar $\mathrm{H}^{+}$-ATPase (19), and an ADH-inducible Na transporter (37).

Specifically the targeting of the Na-Pi cotransporter protein to the apical membrane (exocytosis), and not the internalization from the apical membrane (endocytosis), seems to be dependent on the microtubular network, since pretreatment with colchicine did not prevent the rapid downregulation of BBM Na-Pi cotransport activity and Na-Pi cotransporter protein abundance in response to acute administration of a high phosphate diet. This finding is in agreement with the concept that the endocytic steps of internalization and transport from the plasma membrane to early endosomes do not require microtubules (38). On the other hand, Elkjaer and colleagues reported not only a reduction in endocytic invaginations and en- docytic vacuoles in rat proximal tubules but also an almost completely impaired internalization of the endocytosis tracer horseradish peroxidase upon treatment of rats with colchicine (33). The conflicting results about the effect of colchicineinduced microtubule disruption on endocytosis in rat renal proximal tubules may reflect the existence of different endocytic pathways for the uptake of bulk constituents from the tubular fluid such as glomerularly filtered proteins and retrieval of membrane components such as apical transporters. Moreover, we cannot exclude that the failure of colchicine treatment to completely eliminate microtubules in the subapical region, a phenomenon that was also described by Abate et al. (39), accounts for a remaining functionality of microtubular remnants in favor of an internalization process. Anyhow, the initial step of Na-Pi cotransporter internalization would have to occur along the apical plasma membrane of the brush border microvilli. However, our immunohistochemical data illustrate that the microvilli are devoid of microtubules. Instead, their cytoskeletal core is composed of bundles of microfilaments (40). Therefore, microfilaments may play a central role in the rapid downregulation of Na-Pi cotransport. The dependency of apical endocytosis on intact microfilaments in polarized epithelial cells was already demonstrated by Gottlieb et 

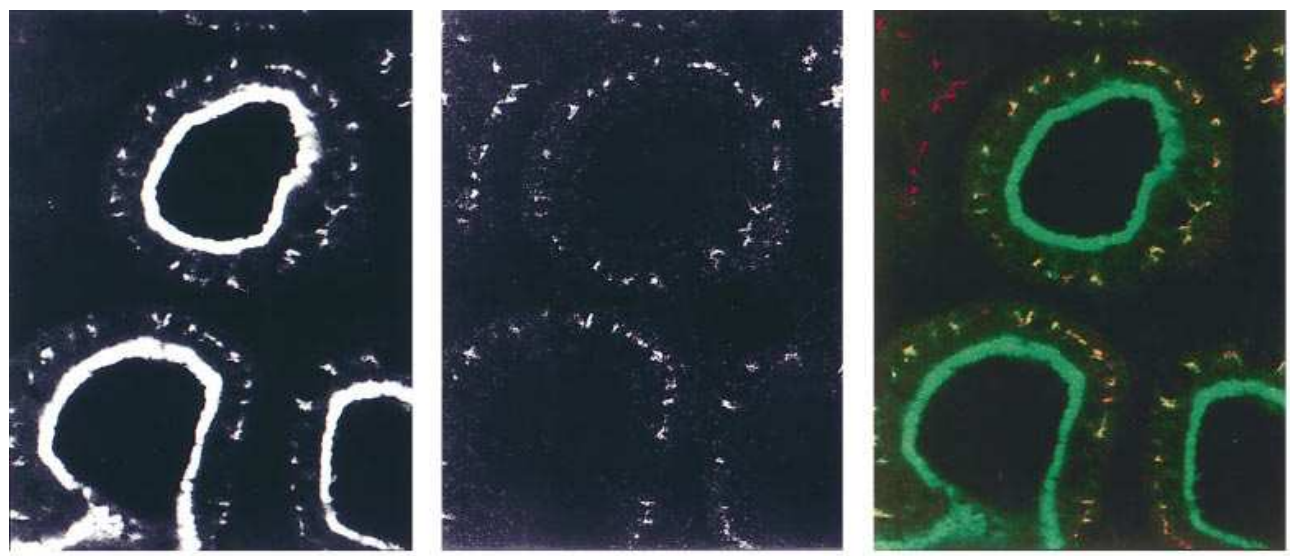

章
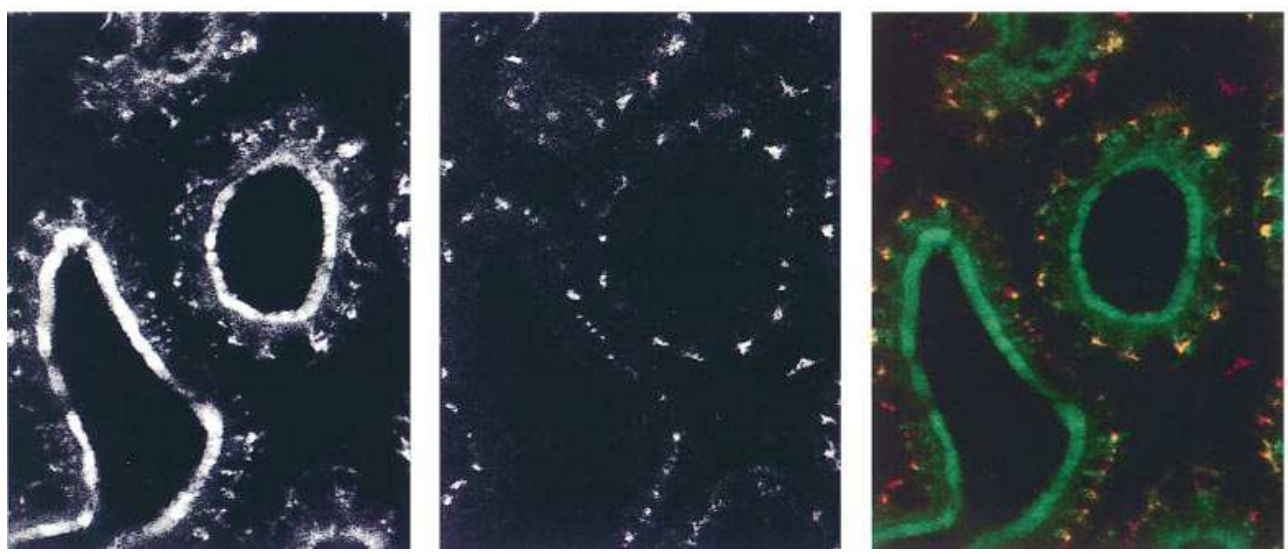

Figure 8. Immunohisto-

chemical localization of intracellular NaPi-2 protein (top) and the Golgi membrane protein 58K (middle) in kidney cryostat sections from rats on a chronic high Pi diet (left) and on an acute low $\mathrm{Pi}$ diet (right). The sections were double-immunostained with green fluorescence for $\mathrm{NaPi}-2$ and red fluorescence for $58 \mathrm{~K}$. Superimposition of the separately recorded images to a color image (bot tom) reveals the spatial colocalization of green and red fluorescence, resulting in yellow color. There is apparent colocalization of the NaPi-2 protein with the Golgi membrane protein $58 \mathrm{~K}$ (bottom).
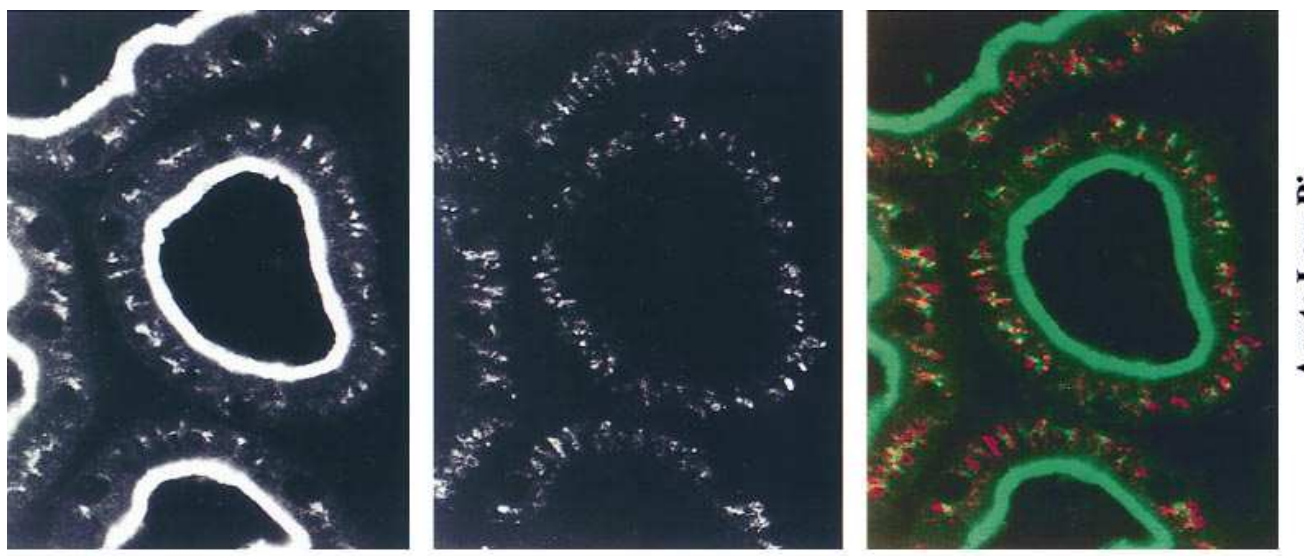

章
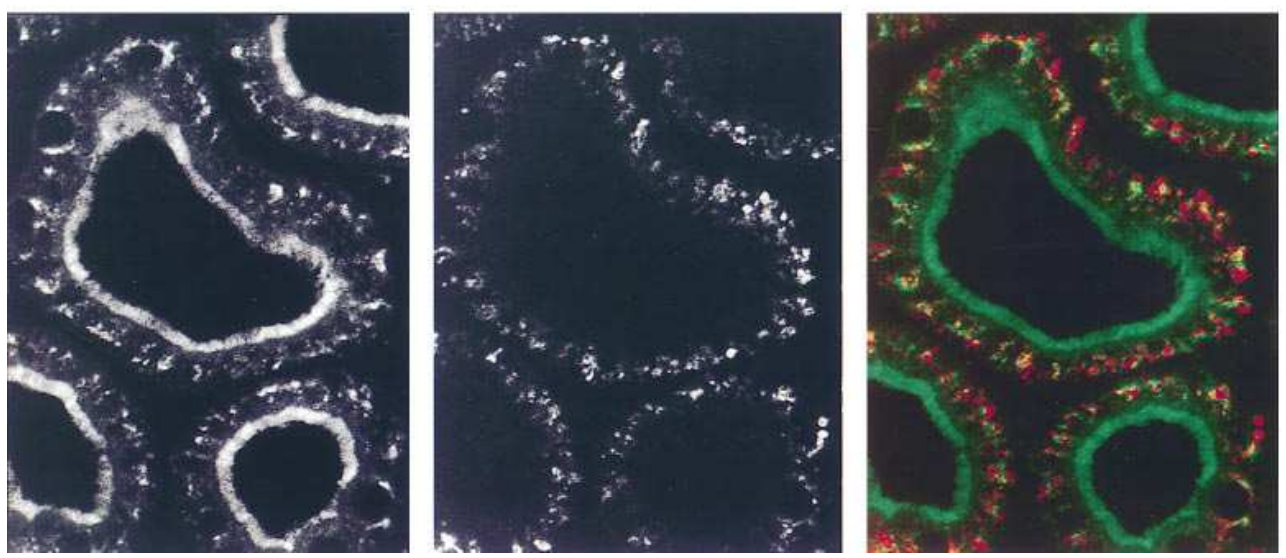

Figure 9. Immunohisto-

chemical localization of intracellular $\mathrm{NaPi}-2$ protein (top) and the lysosomal membrane glycoprotein lgp120 (middle) in kidney cryostat sections from rats on a chronic high $\mathrm{Pi}$ diet (left) and on an acute low Pi diet (right). The sections were double-immunostained with green fluorescence for $\mathrm{NaPi}-2$ and red fluorescence for $\operatorname{lgp} 120$. There is very minimal to absent colocalization of the NaPi-2 protein with the lysosomal membrane protein lgp120 (bottom). 

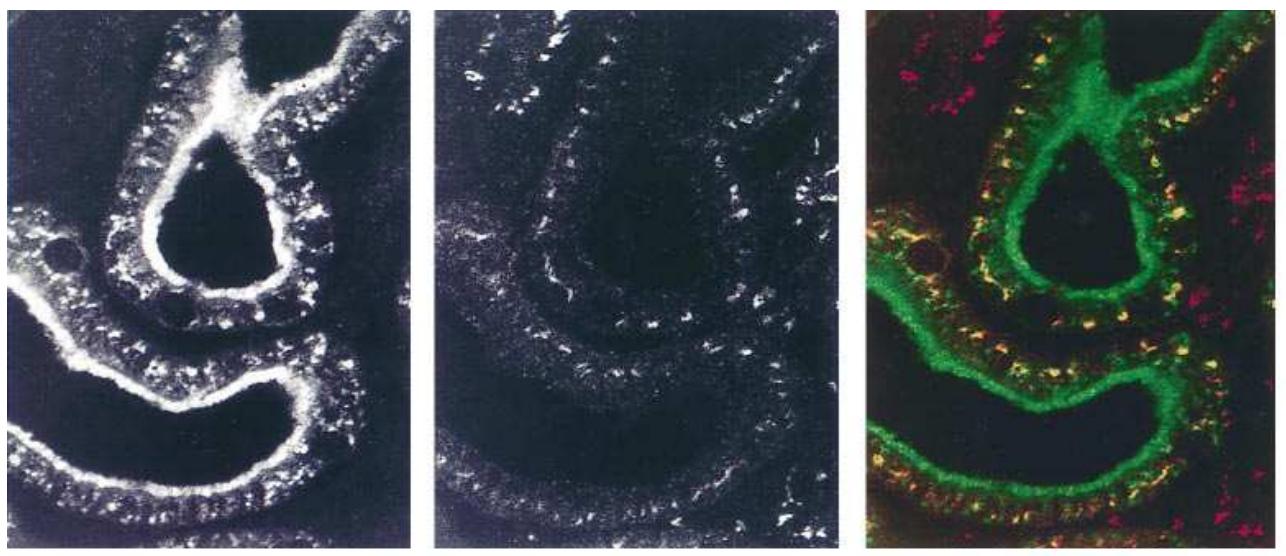

苟
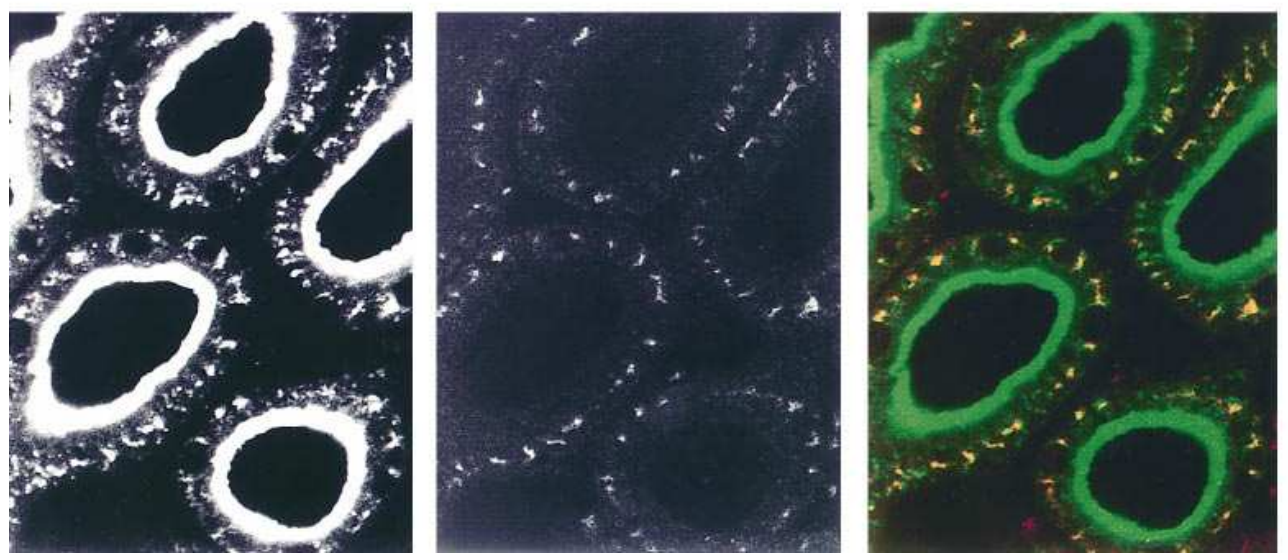

Figure 10. Immunohisto-

chemical localization of intracellular $\mathrm{NaPi}-2$ protein (top) and the Golgi membrane protein 58K (middle) in kidney cryostat sections from rats on a chronic low Pi diet (left) and on an acute high Pi diet

(right). There is apparent colocalization of the $\mathrm{NaPi}-2$ protein with the Golgi membrane protein $58 \mathrm{~K}$ (bottom).
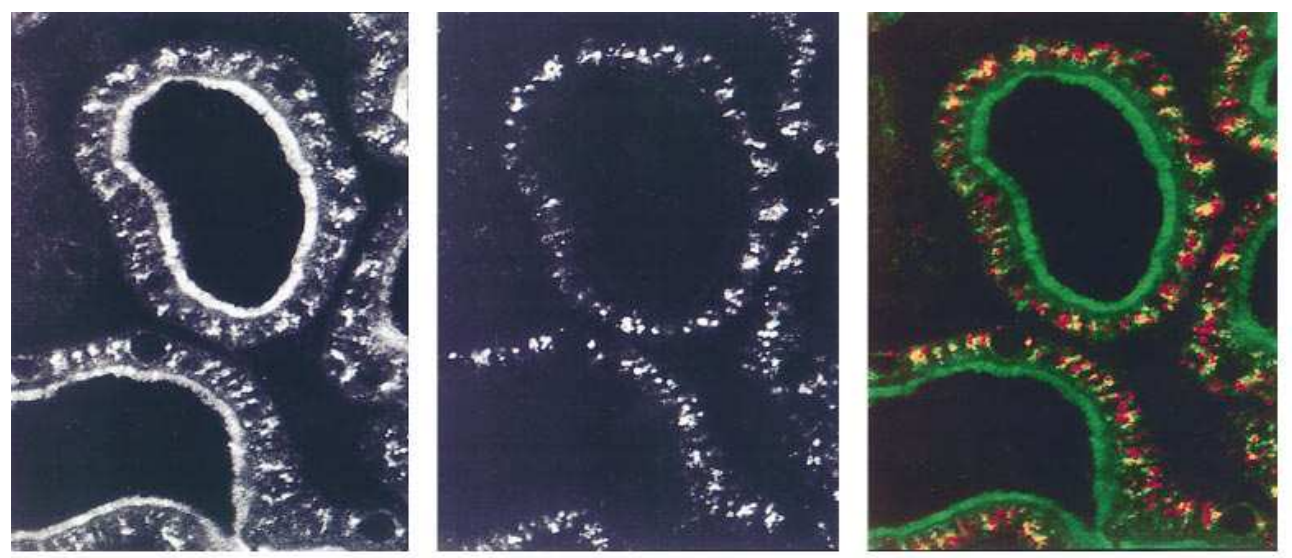

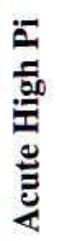
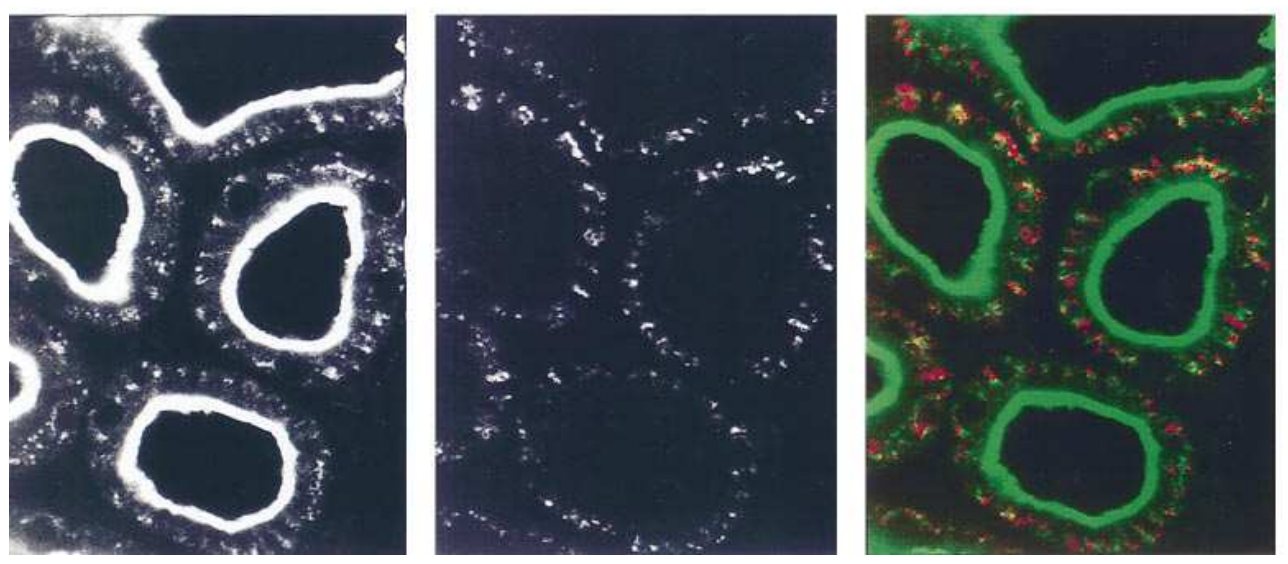

Figure 11. Immunohistochemical localization of intracellular NaPi-2 protein (top) and the lysosomal membrane protein lgp120 (middle) in kidney cryostat sections from rats on a chronic low Pi diet (left) and on an acute high Pi diet (right). There is a strong colocalization of the NaPi-2 protein with the lysosomal membrane protein (bottom). 
al. (41). In their experiments, they disrupted the microfilaments of MDCK cells with cytochalasin D. Yet, the effect of cytochalasin D in vivo on the rat kidney cannot be studied secondary to severe systemic hypotension and mortality of the rats (42). This approach to determine the role of microfilaments in the rapid downregulation of renal Na-Pi cotransport thus has to await a suitable cell culture model.

In summary, the rapid adaptive increase in renal proximal tubular apical BBM Na-Pi cotransport activity and $\mathrm{Na}-\mathrm{Pi}$ cotransporter protein abundance occurs by a cellular mechanism which is independent of de novo protein synthesis and is mediated by microtubule-dependent translocation of presynthesized $\mathrm{Na}-\mathrm{Pi}$ cotransporter protein to the apical BBM.

\section{Acknowledgments}

The authors thank Dr. Ira Mellman for providing the antibody against lgp120. The authors thank Sandra Nickerson and Teresa Autrey (from the Dallas VAMC Medical Service) for secretarial assistance, and Tim Civick (from the Dallas VAMC Medical Media Department) and Christian Gasser (from the Institute of Physiology, University of Zürich) for the illustrations.

This work was supported by grants from the DVA Merit Review and National Kidney Foundation (M. Levi), and the Swiss National Science Foundation grants 31-34010.92 (to B. Kaissling) and 3230785.91 (to H. Murer).

\section{References}

1. Stoll, R., R. Kinne, and H. Murer. 1979. Effect of dietary phosphate intake on phosphate transport by isolated rat renal brush-border vesicles. Biochem. J. 180:465-470.

2. Kempson, S.A., and T.P. Dousa. 1979. Phosphate transport across renal cortical brush border membrane vesicles from rats stabilized on a normal, high or low phosphate diet. Life Sci. 24:881-888.

3. Barrett, P.Q., J.M. Gertner, and H. Rasmussen. 1980. Effect of dietary phosphate on transport properties of pig renal microvillus vesicles. Am. J. Physiol. 239:F352-F359.

4. Cheng, L., G.T. Liang, and B. Sacktor. 1983. Phosphate uptake by renal membrane vesicles of rabbits adapted to high and low phosphorus diets. Am. J. Physiol. 245:F175-F180.

5. Levi, M., B.M. Baird, and P.V. Wilson. 1990. Cholesterol modulates rat renal brush border membrane phosphate transport. J. Clin. Invest. 85:231-237.

6. Caverzasio, J., C.D.A. Brown, J. Biber, J.P. Bonjour, and H. Murer. 1985. Adaptation of phosphate transport in phosphate-deprived LLC-PK 1 cells. Am. J. Physiol. 248:F122-F127.

7. Biber, J., J. Forgo, and H. Murer. 1988. Modulation of $\mathrm{Na}^{+}-\mathrm{P}_{\mathrm{i}}$ cotransport in opossum kidney cells by extracellular phosphate. Am. J. Physiol. 255:C155C161.

8. Biber, J., and H. Murer. 1985. Na- $\mathrm{P}_{\mathrm{i}}$ cotransport in $\mathrm{LLC}^{-\mathrm{PK}_{1}}$ cells: fast adaptive response to $\mathrm{P}_{\mathrm{i}}$ deprivation. Am. J. Physiol. 249:C430-C434.

9. Levi, M., M. Lötscher, V. Sorribas, M. Custer, M. Arar, B. Kaissling, H. Murer, and J. Biber. 1994. Cellular mechanisms of acute and chronic adaptation of rat renal $\mathrm{P}_{\mathrm{i}}$ transporter to alterations in dietary $\mathrm{P}_{\mathrm{i}}$. Am. J. Physiol. 267:F900F908.

10. Shah, S.V., S.A. Kempson, T.E. Northrup, and T.P. Douse. 1979. Renal adaptation to a low phosphate diet in rats. Blockade by actinomycin D. J. Clin. Invest. 64:955-966.

11. Gilbert, T., A. Le Bivic, A. Quaroni, and E. Rodriguez-Boulan. 1991. Microtubular organization and its involvement in the biogenetic pathways of plasma membrane proteins in Caco-2 intestinal epithelial cells. J. Cell Biol. 2: $275-288$.

12. Mills, J.W., E.M. Schwiebert, and B.A. Stanton. 1994. The cytoskeleton and membrane transport. Curr. Opin. Nephrol. Hypertens. 3:529-534.

13. Mays, R.W., K.A. Beck, and W.J. Nelson. 1994. Organization and function of the cytoskeleton in polarized epithelial cells: a component of the protein sorting machinery. Curr. Opin. Cell Biol. 6:16-24.

14. Lafont, F., J.K. Burkhardt, and K. Simons. 1994. Involvement of microtubule motors in basolateral and apical transport in kidney cells. Nature (Lond.). 372:801-803.

15. Mills, J.W., and L.J. Mandel. 1994. Cytoskeletal regulation of membrane transport events. FASEB (Fed. Am. Soc. Exp. Biol.) J. 8:1161-1165.

16. Cole, N.B., and J. Lippincott-Schwartz. 1995. Organization of organelles and membrane traffic by microtubules. Curr. Opin. Cell Biol. 7:55-64

17. Nunnari, J., and P. Walter. 1996. Regulation of organelle biogenesis. Cell. 84:389-394.

18. Levine, B.S., L.D. Ho, K. Pasiecznik, and J.W. Coburn. 1986. Renal adaptation to phosphorus deprivation: characterization of early events. J. Bone Miner. Res. 1:33-40.

19. Brown, D., I. Sabolic, and S. Gluck. 1991. Colchicine-induced redistribution of proton pumps in kidney epithelial cells. Kidney Int. 33:S79-S83.

20. Levi, M., D.M. Jameson, and B.W. Van der Meer. 1989. Role of BBM lipid composition and fluidity in impaired renal Pi transport in aged rat. Am. J. Physiol. 256:F85-F94.

21. Laemmli, U.K. 1970. Cleavage of structural proteins during assembly of the head of the bacteriophage $\mathrm{T}_{4}$. Nature (Lond.). 227:680-685.

22. Towbin, H., T. Staehelin, and J. Gordon. 1979. Electrophoretic transfer of proteins from polyacrylamide gels to nitrocellulose sheets: procedure and some applications. Proc. Natl. Acad. Sci. USA. 76:4350-4354.

23. Custer, M., M. Lötscher, J. Biber, H. Murer, and B. Kaissling. 1994. Expression of Na-Pi co-transport in rat kidney: localization by RT-PCR and immunohistochemistry. Am. J. Physiol. 266:F767-F774.

24. Bloom, G.S., and T.A. Brashear. 1989. A novel 58-kDa protein associates with the Golgi apparatus and microtubules. J. Biol. Chem. 264:1608316092.

25. Donaldson, J.G., J. Lippincott-Schwartz, G.S. Bloom, T.E. Kreis, and R.D. Klausner. 1990. Dissociation of a $110-\mathrm{kD}$ peripheral membrane protein from the Golgi apparatus is an early event in Brefeldin A action. J. Cell Biol. 111:2295-2306.

26. Ktistakis, N.T., M.G. Roth, and G.S. Bloom. 1991. PtK1 cells contain a nondiffusible dominant factor that makes the Golgi apparatus resistant to Brefeldin A. J. Cell Biol. 113:1009-1023.

27. Lewis, V., S.A. Green, M. Marsh, P. Vihko, A. Helenius, and I. Mellman. 1985. Glycoproteins of the lysosomal membrane. J. Cell Biol. 100:18391847.

28. Green, S.A., K.P. Zimmer, G. Griffiths, and I. Mellman. 1987. Kinetics of intracellular transport and sorting of lysosomal membrane and plasma membrane proteins. J. Cell Biol. 105:1227-1240.

29. Howe, C.L., B.L. Granger, M. Hull, S.A. Green, C.A. Gabel, A. Helenius, and I. Mellman. 1988. Derived protein sequence, oligosaccharides, and membrane insertion of the $120-\mathrm{kDa}$ lysosomal membrane glycoprotein (lgp120): identification of highly conserved family of lysosomal membrane glycoproteins. Proc. Natl. Acad. Sci. USA. 85:7577-7581.

30. Harter, C., and I. Mellman. 1992. Transport of the lysosomal membrane glycoprotein lgp120 (lgp-A) to lysosomes does not require appearance on the plasma membrane. J. Cell Biol. 117:311-325.

31. Markovich, D., T. Verri, V. Sorribas, J. Forgo, J. Biber, and H. Murer. 1995. Regulation of opossum kidney (OK) cell Na/Pi cotransport by Pi deprivation involves mRNA stability. Pflügers Arch. 430:459-463.

32. Gutmann, E.J., J.L. Niles, R.T. McClusky, and D. Brown. 1989. Colchicine-induced redistribution of an endogenous apical membrane glycoprotein (gp 330) in kidney proximal tubule epithelium. Am. J. Physiol. 257:C397-C407.

33. Elkjaer, M.L., H. Birn, P. Agre, E.I. Christensen, and S. Nielsen. 1995. Effects of microtubule disruption on endocytosis, membrane recycling and polarized distribution of Aquaporin-1 and gp330 in proximal tubule cells. Eur. J. Cell Biol. 67:57-72.

34. Katsura, T., J.M. Verbavatz, J. Farinas, T. Ma, D.A. Ausiello, A.S. Verkman, and D. Brown. 1995. Constitutive and regulated membrane expression of aquaporin 1 and aquaporin 2 water channels in stably transfected LLCPK1 epithelial cells. Proc. Natl. Acad. Sci. USA. 92:7212-7216.

35. Nielsen, S., C.L. Chou, D. Marples, E.I. Christensen, B.K. Kishore, and M.A. Knepper. 1995. Vasopressin increases water permeability of kidney collecting duct by inducing translocation of aquaporin-CD water channels to plasma membrane. Proc. Natl. Acad. Sci. USA. 92:1013-1017.

36. Fuller, C.M., R.J. Bridges, and D.J. Benos. 1994. Forskolin- but not ionomycin-evoked CI secretion in colonic epithelia depends on intact microtubules. Am. J. Physiol. 266:C661-C668.

37. Verrey, F., P. Groscurth, and U. Bolliger. 1995. Cytoskeletal disruption in A6 kidney cells: impact on endo/exocytosis and $\mathrm{NaCl}$ transport regulation by antidiuretic hormone. J. Membr. Biol. 145:193-204.

38. Gruenberg, J., G. Griffiths, and K.E. Howell. 1989. Characterization of the early endosome and putative endocytic carrier vesicles in vivo and with assay of vesicle fusion in vitro. J. Cell Biol. 108:1301-1316.

39. Abate, M., J.V. Bonventre, and D. Brown. 1994. The microtubule network of renal epithelial cells is disrupted by ischemia and reperfusion. Am. J. Physiol. 267:F971-F978.

40. Coudrier, E., D. Kerjaschki, and D. Louvard. 1988. Cytoskeleton organization and submembranous interactions in intestinal and renal brush borders. Kidney Int. 34:309-320.

41. Gottlieb, T.A., I.E. Ivanov, M. Adesnik, and D.D. Sabatini. 1993. Actin microfilaments play a critical role in endocytosis at the apical but not the basolateral surface of polarized epithelial cells. J. Cell Biol. 120:695-710.

42. Kellermann, P.S., R.A.F. Clark, C.A. Hoilien, S.L. Linas, and B.A. Molitoris. 1990. Role of microfilaments in maintenance of proximal tubule structural and functional integrity. Am. J. Physiol. 259:F279-F285. 